\title{
Review Article \\ Novel Tools for Prostate Cancer Prognosis, Diagnosis, and Follow-Up
}

\author{
Andreas Dimakakos, Athanasios Armakolas, and Michael Koutsilieris \\ Physiology Laboratory, Medical School, National and Kapodistrian University of Athens, Mikras Asias 75, 11527 Athens, Greece \\ Correspondence should be addressed to Michael Koutsilieris; mkoutsil@med.uoa.gr
}

Received 7 February 2014; Accepted 9 April 2014; Published 4 May 2014

Academic Editor: Giovanni Luca Gravina

Copyright ( 2014 Andreas Dimakakos et al. This is an open access article distributed under the Creative Commons Attribution License, which permits unrestricted use, distribution, and reproduction in any medium, provided the original work is properly cited.

Prostate-specific antigen (PSA) is the main diagnostic tool when it comes to prostate cancer but it possesses serious limitations. Therefore, there is an urgent need for more sensitive and specific biomarkers for prostate cancer prognosis and patient followup. Recent advances led to the discovery of many novel diagnostic/prognostic techniques and provided us with many worthwhile candidates. This paper briefly reviews the most promising biomarkers with respect to their implementation in screening, early detection, diagnostic confirmation, prognosis, and prediction of therapeutic response or monitoring disease and recurrence; and their use as possible therapeutic targets. This review also examines the possible future directions in the field of prostate cancer marker research.

\section{Introduction}

Prostate cancer is the sixth leading cause of cancer-related death in men (it is now the second in the United States and first in the UK) [1]. While there are exceptions, it is not a particularly aggressive form of cancer, and it tends to metastasize mainly to bones and lymph nodes [2]. Many factors have been proven to be implicated in the development of prostate cancer, including diet and genetics. Curative treatment generally involves surgery, various forms of radiation therapy, or, less commonly, cryosurgery. Hormonal therapy and chemotherapy are not usually implemented, unless the disease reaches advanced stages and there have been instances where hormonal therapy has been combined with radiation therapy [3].

Over the years, many markers have been used for the diagnosis and follow-up of prostate cancer. Prostate-specific antigen (PSA) is the most common marker used for prostate cancer detection and follow-up, and until recently, PSA was considered the most reliable marker to predict prostate cancer [4]. In 1994, the FDA approved the use of the PSA test in conjunction with a digital rectal exam (DRE) to test asymptomatic men for prostate cancer. Blood PSA levels higher than $4.0 \mathrm{ng} / \mathrm{mL}$ is an indication of prostate cancer.
Studies have shown that the levels of free PSA in the serum act as a more accurate marker for $\mathrm{BPH}$, while the levels of $\alpha 1$-antichymotrypsin-PSA complex more accurately predict prostate cancer [5].

Lately, however, PSA screening has fallen under controversy since it is detected in $30-50 \%$ of the cases of benign prostate hyperplasia $[\mathrm{BPH}]$ and in only $20 \%$ of the cases of prostate cancer. Recent evidence suggests that some prostate cancer patients may present PSA levels below $4.0 \mathrm{ng} / \mathrm{mL}$, while PSA levels can be affected by various other factors, such as prostatitis, urinary tract infection, and benign prostate hyperplasia $(\mathrm{BPH})[6-8]$. Additionally, a variety of drugs ( $5 \alpha-$ reductase inhibitors, that is, finasteride and dutasteride) used to treat $\mathrm{BPH}$ reduce PSA in the blood [9].

Out of the men that display elevated PSA levels in the blood, only $25 \%$ are associated with prostate cancer. In order to get more accurate readings on the association between PSA levels and prostate cancer, other factors are taken into consideration, such as free versus total PSA, age (PSA increases with age), PSA velocity and doubling time, pro-PSA, and PSA density of the transition zone $[6-8,10]$. Velocity refers to the rate of change in a man's PSA level over time, expressed in $(\mathrm{ng} / \mathrm{mL}) /$ year, while doubling time refers to the period of time in which the concentration of 
PSA in the blood doubles. Pro-PSA refers to several inactive PSA precursors that have been suggested to more strongly associate with prostate cancer, while PSA density refers to the blood level of PSA divided by the volume of the interior part of the prostate that surrounds the urethra transition zone.

The absence of a reliable marker for prostate cancer diagnosis and follow-up creates the demand for novel, specific, sensitive, and cost effective biological markers. In this review, we are going to focus on novel biological markers for prostate cancer prognosis and patient follow-up and the possibility to be targeted as markers for prostate cancer treatment.

\section{The Ideal Marker}

Only a few markers have managed to withstand the test of time and entered into clinical trials. The main characteristics of an ideal tumor marker are its specificity for a given tumor type and its sensitivity, and it should also provide advance warning before clinical diagnosis. The levels of the marker should accurately depict the progress or regression of the target tumor. A short half-life would allow for frequent serial measurements. Finally, the detection test should be cheap and noninvasive, so as to allow patient screening and also to be acceptable by the majority of the patients. Finally, tumorassociated markers should be able to predict the metastatic onset or, in advanced stages, determine the metastatic spread [11].

\section{Current Prostate Cancer Markers}

The rapid advancements in overall detection techniques have made it possible to identify a large number of new possible biomarkers; however, a recent study on prostate cancer tissue samples has shown that the equivalence between RNA transcripts and protein products ranges only between $48 \%$ and $64 \%$ [12]. Since proteins are the true functional molecules of the cell, much of the current research has shifted towards the definition of solely protein markers. The most promising prostate cancer markers among others are the prostate-specific membrane antigen (PSMA), prostate stem cell antigen (PSCA), early prostate cancer antigen (EPCA), enhancer of zeste homolog gene 2 (EZH2), and the urokinase plasminogen activator (uPA) $[13,14]$.

The PSMA is a type II integral membrane glycoprotein, originally identified in 1987 as being significantly overexpressed in the epithelial cells of prostate cancer patients. Since then, it has undergone multiple evaluations with mixed results. The sensitivity and specificity of PSMA in distinguishing prostate adenocarcinoma from any other type of malignancy are $65.9 \%$ and $94.5 \%$, respectively. Some believe that it can be utilized to check the progress of the disease posttreatment. It can also take part in the radiologic imaging of prostate cancer and has been studied as a possible target for monoclonal antibodies to combat prostate cancer, due to its overexpression, despite the fact that its function in prostate cancer is still unclear [15-21].

The PSCA is a prostate-specific glycosyl phosphatidylinositol-anchored glycoprotein expressed on the cell surface.
Several studies have shown correlation between increased levels of PSCA and prostate cancer presence, stage, progression, and metastases. Moreover, PSCA RNA is detectable in the peripheral blood through the use of real-time PCR (RTPCR), an aspect that has been implemented in circulating tumor cell (CTC) detection, while the protein product can act as a target for monoclonal antibodies, as it is situated on the tumor cell surface. As a result, it is a very promising biological marker [22, 23].

The EPCA is a prostate cancer-associated nuclear structural protein. A blood test using an EPCA enzyme-linked immunosorbent assay has displayed 92\% sensitivity and 94\% specificity for prostate cancer, suggesting a possibly immensely useful biomarker [24].

The EZH2 is a member of the polycomb group of proteins, and it is involved in maintaining the transcriptional repressive state of genes over successive cell generations. $\mathrm{EZH} 2$ acts mainly as a gene silencer. EZH2 overexpression may promote cancer due to increase in histone methylation which silences the expression of tumor suppressor genes. Its expression is significantly increased in metastatic prostate cancer in comparison to localized prostate cancer and in localized prostate cancer in comparison to benign prostate tissue [25]. Currently, there is no blood test for EZH2, but it could prove to be a useful biological marker to identify patients at risk of metastasis [13].

The uPA axis is involved in various phases of tumor development and so could act as a potential treatment target. Results show that elevated circulating levels of uPA and uPA receptor ( $\mathrm{UPAR}$ ) are connected with prostate cancer stage and bone metastases. Additionally, uPA has been described as a strong predictor of recurrence after radical prostatectomy [26-28].

Transmembrane protease serine 2 (TMPRSS2) is an enzyme that in humans is encoded by the androgen-regulated TMPRSS2 gene. Its function in prostate cancer lies in the overexpression of E26 transformation-specific (ETS) transcription factors, such as ETS-related gene (ERG) and ETS translocation variant 1 (ETV1) through gene fusion [29]. TMPRSS2-ERG fusion gene is frequently present in human prostate cancer $(50 \%)$ and it is not detected in normal prostate or $\mathrm{BPH}$ [30-33]. It has been suggested that ERG overexpression facilitates prostate cancer progression by promoting androgen independence through disruption of androgen-receptor signaling [29]. Noninvasive detection of TMPRSS2-ERG transcripts is possible in urinary sediments through real-time PCR, presenting a 93\% specificity for prostate cancer. This technique is usually carried out in combination with and after digital rectal examination (DRE) [34]. Once combined with prostate cancer antigen 3 (PCA3), the sensitivity increases from $62 \%$ (PCA3 alone) to $72 \%$ (combined) without sacrificing any of the specificity $[35,36]$. These facts constitute TMPRSS2-ERG, a powerful diagnostic tool on its own and a viable way to improve the efficiency of other promising biomarkers.

Studies with general cancer markers are also being performed to determine a possible connection with prostate cancer, aiming to provide accuracy in prostate cancer detection when used solely or in combination with one of the prostate 
cancer specific markers. The most promising general cancer markers for prostate cancer detection are transforming growth factor- $\beta 1$ (TGF- $\beta 1$ ) and interleukin-6 (IL-6). TGF- $\beta 1$ is involved in cellular proliferation, redifferentiation, angiogenesis, and epithelial to mesenchymal transition (EMT), the process by which epithelial cells lose cell polarity and cellto-cell adhesion, gaining migratory and invasive properties, and it has been associated with metastasis in prostate cancer models [37-41]. However, the results are inconclusive regarding its correlation to prostate cancer progression [42, 43]. IL6 is a cytokine with a large number of biological activities, including regulation of immune response. It has been shown to stimulate cell growth in androgen-independent prostate cancer cells but inhibit it in androgen-dependent prostate cancer cells $[44,45]$. Recent studies have introduced the idea of the combined use of TGF- $\beta 1$ and IL- 6 to improve the chances of accurately predicting lymph node metastases $[46,47]$.

Studies have shown that E-cadherin loss correlates with prostate tumor progression, establishing E-cadherin as a prognosis factor for clinical disease progression [48]. On the other hand, the elevation of $\mathrm{N}$-cadherin has been shown to be a significant predictor of prostate cancer recurrence following radical prostatectomy, making it one of the few biomarkers capable of providing information for prostate cancer treatment follow-up [40, 49]. Additional data has shown significant correlation between elevated ZEB1 expression, induced by androgens, and high Gleason scores in prostate cancer [50]. This means that ZEB1 could function as a possible biomarker for predicting the onset of metastatic spread in prostate cancer.

The cancer cells subjected to EMT develop stem-cell-like qualities, practically becoming circulating stem cells. These cells exhibit both tumor and mesenchymal markers [51]. The existence of malignant cells of epithelial origin in the blood, the CTCs, has been known for over a century and has been associated with metastasis. Circulating tumor cell (CTC) counts in the blood have been suggested to act as prostate cancer prognostic markers, especially in cases with bone metastases [52-55]. Over the past few years, different approaches have been developed prior to the detection of CTCs in different tumors. Each of these approaches has distinct advantages and disadvantages, with the most notable being sensitivity and specificity [21, 51, 56-58]. At the moment, there are diagnostic platforms designed to detect CTCs in order to ascertain, up to a point, whether chemotherapy was successful and if there is going to be a cancer recurrence $[52,56]$.

\section{The IGF System}

The insulin-like growth factor (IGF)/insulin family of growth factors is a system which plays a critical role in the development and growth of several tissues as well as the overall metabolism. It is comprised of three different receptors: the IGF-1 receptor (IGF-1R), IGF-2 receptor (IGF-2R), and the insulin receptor (IR), three different ligands (IGF-1, IGF2 , and insulin), and six types of circulating IGF-binding proteins (IGFBP1-6) [59, 60].
So far, the scientific community is convinced, without data to the contrary, that the IGF-1 system is not, by its nature, oncogenic. The activated receptors are not genotoxic nor do they cause DNA mutations or any other kind of DNA damage [61]. However, they do severely affect the progress of the cell cycle, pushing cells to proliferate at an alarming rate, once their regulation is influenced, like in cases of cancer.

There have been attempts in the past to ascertain whether any part of the IGF axis (ligands, receptors, or binding proteins) could be used as a reliable biological marker for prostate cancer and prostate cancer metastases with controversial results $[62,63]$. Since elevated IGF-1 and IGF-1R levels have been associated with many types of cancer and metastases, they cannot be used as prostate cancer markers, at least individually, due to their lack of specificity $[59,60,63-$ 65]. Certain data showed that the PSA/IGF-1 ratio could differentiate between prostate cancer and BPH but was met with criticism [66]. So far, IGF-1, IGF-1R, and IGFBP3 levels have only been shown to be possible but deficient prostate cancer risk markers. However, there is data that supports the idea that IGF-1 and IGF-1R could be used as biomarkers for advanced stages of prostate cancer and prostate cancer metastases $[63,65,67]$. This could be significant, as compared to some of the other possible biomarkers mentioned.

The phosphorylation of the receptor through the binding of the ligands leads indirectly to the activation of the MAPK/ERK, AKT, and RAS/RAF pathways. This makes the IGF-1R an ideal target for several experimental treatments $[59,60,68]$. Anticancer strategies focusing on the IGF1 signaling system usually belong in one of two categories: neutralizing antibodies and small molecule inhibitors of the IGF-1R kinase activity. Some of them are now being tested at a clinical level, in tandem with standard chemotherapeutic or targeted agents in cancer patients.

Monoclonal antibodies targeting IGF-1R usually target its extracellular domain. Binding of these antibodies has the added effect of downregulating IGF-1R by promoting its internalization. Most antibodies that have been tested in clinical trials have shown no adverse reactions [69]. It was not known until recently that although these antibodies inhibit the binding of the IGF-1 to the IGF-1R, they also activate the IGF-1R (to a lesser extent) by binding to it [70, 71]. A solution to that suggests the use of these antibodies in combination with other antibodies or therapeutic factors targeting the IGF-1R intracellular pathways.

However, IGF-1R is not the only part of the IGF1 axis that has been targeted by neutralizing antibodies. There have been attempts in the past to construct anti-IGF-1 monoclonal antibodies with little success $[72,73]$. Nowadays, the focus has shifted entirely towards the IGF-1R.

Along with advancements in analytical technology comes the progress in the characterization of IGF-1R structure [74]. This knowledge facilitates the design and use of small molecule inhibitors targeting IGF-1R. However, it is vitally important that there is no cross-reactivity between them and IR. At the moment, most of these small molecule inhibitors either display high levels of toxicity or they have not made it past stage II clinical trials [67, 75-78]. 
The anticancer strategies focusing on the IGF-1 system are still in the early stages of research, but their effects on prostate cancer were not associated with a spectacular success. The absence of an alternative, better than PSA, prostate cancer marker, leads to the consideration of other venues of research.

\section{A Glimpse at the Future}

The ideal prostate cancer marker has not been discovered yet. Sometimes, however, just one marker is not enough. This fact gave rise to the idea that the use of multiple markers at the same time could provide improved results. Tumorassociated antigens stimulate the production of autoantibodies (antibodies targeting an individual's own proteins) against cancer [79-82]. The measurement of different anti-tumor autoantibodies, through the use of protein microarrays, is expected to give us autoantibody signatures, that could prove to be a very accurate analytical tool for prostate cancer diagnosis, prognosis, and patient follow-up [83, 84].

Another promising approach towards the discovery of markers, more specific and sensitive than PSA, is the largescale analysis of prostate cancer proteins, regarding their structures and functions, by proteomics [85]. Several biological sources, including tissues, urine, serum, plasma, and prostatic fluids, are currently under investigation using highthroughput proteomic platforms, such as nanoparticle capture based analysis, for that exact purpose [86]. Secretomics, a subfield of proteomics that studies secreted proteins and secretion pathways using proteomic approaches, has recently emerged as an important tool for the discovery of biomarkers of disease [87].

The prostate has been known for a long time to display unique metabolic profiles $[88,89]$. Metabolomics is the study of chemical processes involving metabolites. It is the study of the unique chemical fingerprint that a specific cellular process leaves behind. More specifically, the prostate is unique among human organs due to the high levels of citrate in the prostatic fluid levels that can be 200-700 times higher than the ones in the blood plasma. However, when the prostate is subjected to neoplastic transformation, the prostate's reserves of citrate are depleted due to the increased energy consumption by the rapidly proliferating cancer cells $[90,91]$.

Quite recently, certain results showed not only that sarcosine, also known as $\mathrm{N}$-methylglycine, an intermediate and byproduct in glycine synthesis and degradation, could be used as a dynamic new biomarker for prostate cancer metastasis, but also that sarcosine levels could control the invasiveness of the cancer. Since then, these results have been widely disputed, while there is doubt that sarcosine is actually an appropriate prostate cancer marker [92-95].

Another marker related to prostate cancer that has surfaced from the realm of metabolomics is choline, a water-soluble essential nutrient. Studies have shown that prostate cancer tissue displays elevated levels of choline and its component metabolites (free choline, phosphocholine, and glycerophosphocholine), in comparison with healthy prostate tissue. These changes reflect enhanced synthesis and degradation of phospholipid membranes. Additionally, levels of choline-containing metabolites are higher in metastatic tissues, when compared to the primary prostate cancer [89, 96-99], indicating the possible use of choline as a prostate cancer progression marker.

Recently, the field of epigenetic modifications has proven to be of interest when it comes to prostate cancer, as they have been connected with both disease initiation and progression [100, 101]. More specifically, DNA-methylation, histone modifications, and microRNA (miRNA) alterations occur at a much higher frequency than mutations and are present at premalignant stages of the disease, making them promising biomarkers [102].

Currently, the most extensively studied methylationbased markers in prostate cancer are the hypermethylated glutathione S-transferase P1 (GSTP1) and Ras-association domain family protein isoform A (RASSF1A). GSTP1 is involved in the cellular protection system against toxic effects and is especially promising as a biomarker because it is highly specific for prostate cancer (>90\%); levels of GSTP1 methylation are associated with different stages of the disease; levels of GSTP1 promoter region methylation can differentiate between prostate cancer and BPH and they are detectable by noninvasive means in body fluids [103106]. The methylation of RASSF1A, on the other hand, can potentially be used to distinguish aggressive tumors from indolent ones [107].

Histone modifications have not been researched to the same extent as methylation-based markers, mostly due to the absence of highly sensitive detection methods [108]. Currently, immunohistochemistry is the only method available for the study of histone modifications, with ELISA being an as of yet unproven alternative [109]. So far, the levels of specific histone modifications, such as H3K18Ac, H4K12Ac, $\mathrm{H} 3 \mathrm{~K} 4 \mathrm{Me} 2$, and H4R3Me2, have been shown to correlate with prostate cancer tumor stage [110]; but without a reliable method to detect these modifications in biological fluids, progress has been slow. It is clear that this aspect of epigenetic modifications requires further research.

miRNA is also another promising candidate for prostate cancer prognosis and therapy. The mature miRNAs are short, noncoding, single-stranded RNA molecules that bind to complementary sequences in the $3^{\prime}$ UTR of target mRNAs, usually resulting in their silencing. They are detectable in body fluids, such as blood and serum, highly stable due to their placement within microvesicles, and thought to be, in most cases, tumor specific $[111,112]$. While a large number of miRNAs have been shown to be altered in prostate cancer, the ones that have displayed the most promise are miR-141 and miR-375 [36]. Further studies have shown that increased expression of miR-141 and miR-375 is significantly associated with pathological stage and Gleason score [113]. Elevated plasma levels of miR-141 and miR-375 could potentially differentiate patients with metastases from those without [114]. Despite the promising results, miRNA implementation in prostate cancer detection is still in its infancy, mainly due to the difficulties in isolating miRNA from limited biological sources.

However, in our quest of discovering and defining new biomarkers, one must take into account the fact that every individual patient is different than the next. Tumors, most 
commonly, tend to be comprised of multiple cellular clones and this fact may alter the marker expression. There are several lines of evidence in the literature suggesting that the patients' genetic profile could affect patients' response to treatments $[64,115-120]$. Therefore it can be understood that identifying new biological markers is clearly not enough and a point of vital importance is to understand how different genetic alterations can influence cancer, so that the most effective course of treatment can be applied.

\section{Discussion}

Despite the fact that NCI does not have such guidelines that suggest the use of markers in cancer, the American Society of Oncology and the National Academy of Clinical Biochemistry have published clinical practice guidelines for markers on a variety of tumors. There are more than 20 tumor markers currently in use, and only the PSA is used in prostate cancer. For the past few years, PSA has raised quite a cloud when it comes to its effectiveness as a biological marker for the detection of prostate cancer. Its deficiencies have given rise to serious efforts to either improve its specificity by combining it with other existing biomarkers or discover and define new ones and also examine the possibility to use those markers as targets for a therapy influencing the balance between benefits (saved lives) and costs (unnecessary surgery).

There are a number of promising markers displayed here that can be used solely or in combination prior to obtaining the desirable result. Despite that, a recent study where 380 prostate cancer markers from the literature were examined in prostate cancer tissues by microarray analysis indicates that none of the markers examined can compete with PSA for tissue specificity. The markers proposed generally presented great variability of expression in normal and tumor tissue or they were expressed at similar levels in other tissues. Furthermore the evidence of this study suggests that the diagnostic and prognostic testing is more difficult in prostate cancer than in other neoplasms probably due to the fact that the individual genetic variability affects the tumor's outcome [121].

For that reason the research for better markers for prostate cancer has been turned towards different markers such as the autoantibodies raised against some tumor markers and/or different technologies proteomics and metabolomics.

Indeed, many of these markers are still in the realm of possibility; but if we take into account the fact that prostate cancer is globally the sixth cancer-associated cause of death in men, its early detection or proper stratification could really make a difference in the socioeconomic system. Therefore, it is imperative that the proper steps are taken to determine which of these markers, if any, would better suit our needs.

\section{Conflict of Interests}

The authors declare that they have no conflict of interests regarding the publication of this paper.

\section{References}

[1] P. D. Baade, D. R. Youlden, and L. J. Krnjacki, "International epidemiology of prostate cancer: geographical distribution and secular trends," Molecular Nutrition and Food Research, vol. 53, no. 2, pp. 171-184, 2009.

[2] G. N. Thalmann, P. E. Anezinis, S.-M. Chang et al., "Androgenindependent cancer progression and bone metastasis in the LNCaP model of human prostate cancer," Cancer Research, vol. 54, no. 10, pp. 2577-2581, 1994.

[3] E. A. Klein, "Opportunities for prevention of prostate cancer: genetics, chemoprevention, and dietary intervention," Reviews in Urology, vol. 5, supplement 4, pp. S18-S28, 2002.

[4] I. M. Thompson, "PSA: a biomarker for disease. A biomarker for clinical trials. How useful is it?" Journal of Nutrition, vol. 136, no. 10, p. 2704, 2006.

[5] U. H. Stenman, J. Leinonen, H. Alfthan, S. Rannikko, K. Tuhkanen, and O. Alfthan, "A complex between prostatespecific antigen and $\alpha 1$-antichymotrypsin is the major form of prostate-specific antigen in serum of patients with prostatic cancer: assay of the complex improves clinical sensitivity for cancer," Cancer Research, vol. 51, no. 1, pp. 222-226, 1991.

[6] G. L. Andriole Jr., "PSA screening and prostate cancer risk reduction," Urologic Oncology, vol. 30, no. 6, pp. 936-937, 2012.

[7] M. J. Barry, "Evaluation of symptoms and quality of life in men with benign prostatic hyperplasia," Urology, vol. 58, supplement 6, pp. 25-32, 2001.

[8] F. H. Schröder, "PSA screening-a review of recent studies," European Journal of Cancer, vol. 45, no. 1, pp. 402-404, 2009.

[9] I. M. Thompson, C. Chi, D. P. Ankerst et al., "Effect of finasteride on the sensitivity of PSA for detecting prostate cancer," Journal of the National Cancer Institute, vol. 98, no. 16, pp. 1128-1133, 2006.

[10] S. D. Mikolajczyk and H. G. Rittenhouse, "Pro PSA: A more cancer specific form of prostate specific antigen for the early detection of prostate cancer," Keio Journal of Medicine, vol. 52, no. 2, pp. 86-91, 2003.

[11] S. Sharma, “. Tumor markers in clinical practice: general principles and guidelines. Indian journal of medical and paediatric oncology," Official Journal of Indian Society of Medical \& Paediatric Oncology, vol. 30, no. 1, pp. 1-8, 2009.

[12] S. Varambally, J. Yu, B. Laxman et al., "Integrative genomic and proteomic analysis of prostate cancer reveals signatures of metastatic progression," Cancer Cell, vol. 8, no. 5, pp. 393-406, 2005.

[13] T. J. Bradford, S. A. Tomlins, X. Wang, and A. M. Chinnaiyan, "Molecular markers of prostate cancer," Urologic Oncology, vol. 24, no. 6, pp. 538-551, 2006.

[14] S. F. Shariat, A. Semjonow, H. Lilja, C. Savage, A. J. Vickers, and A. Bjartell, "Tumor markers in prostate cancer I: blood-based markers," Acta Oncologica, vol. 50, supplement 1, pp. 61-75, 2011.

[15] J. K. Troyer, M. L. Beckett, and G. L. Wright Jr., "Detection and characterization of the prostate-specific membrane antigen (PSMA) in tissue extracts and body fluids," International Journal of Cancer, vol. 62, no. 5, pp. 552-558, 1995.

[16] J. Q. Ren, Z. Q. Chen, L. Zheng, Q. Chen, H. Li, and H. G. Zhu, "Correlation study of expression levels of prostatespecific membrane antigen and prostate-specific antigen with Gleason score of prostate carcinoma," Zhonghua Zhong liu za zhi [Chinese journal of oncology], vol. 26, no. 12, pp. 735-738, 2004 . 
[17] G. P. Murphy, G. M. Kenny, H. Ragde et al., "Measurement of serum prostate-specific membrane antigen, a new prognostic marker for prostate cancer," Urology, vol. 51, supplement 5, pp. 89-97, 1998.

[18] P. Mhawech-Fauceglia, S. Zhang, L. Terracciano et al., "Prostatespecific membrane antigen (PSMA) protein expression in normal and neoplastic tissues and its sensitivity and specificity in prostate adenocarcinoma: An immunohistochemical study using mutiple tumour tissue microarray technique," Histopathology, vol. 50, no. 4, pp. 472-483, 2007.

[19] R. Kurek, G. Nunez, N. Tselis et al., "Prognostic value of combined "triple"-reverse transcription-PCR analysis for prostatespecific antigen, human kallikrein 2, and prostate-specific membrane antigen mRNA in peripheral blood and lymph nodes of prostate cancer patients," Clinical Cancer Research, vol. 10, no. 17, pp. 5808-5814, 2004.

[20] M. C. Gong, S. S. Chang, M. Sadelain, N. H. Bander, and W. D. W. Heston, "Prostate-specific membrane antigen (PSMA)specific monoclonal antibodies in the treatment of prostate and other cancers," Cancer and Metastasis Reviews, vol. 18, no. 4, pp. 483-490, 1999.

[21] D. C. Chu, C. K. Chuang, Y. F. Liou, R. D. Tzou, H. C. Lee, and C. F. Sun, "The use of real-time quantitative PCR to detect circulating prostate-specific membrane antigen mRNA in patients with prostate carcinoma," Annals of the New York Academy of Sciences, vol. 1022, pp. 157-162, 2004.

[22] Z. Zhigang and S. Wenlv, "Prostate stem cell antigen (PSCA) expression in human prostate cancer tissues: implications for prostate carcinogenesis and progression of prostate cancer," Japanese Journal of Clinical Oncology, vol. 34, no. 7, pp. 414-419, 2004.

[23] Z. Gu, G. Thomas, J. Yamashiro et al., "Prostate stem cell antigen (PSCA) expression increases with high gleason score, advanced stage and bone metastasis in prostate cancer," Oncogene, vol. 19, no. 10, pp. 1288-1296, 2000.

[24] B. Paul, R. Dhir, D. Landsittel, M. R. Hitchens, and R. H. Getzenberg, "Detection of prostate cancer with a blood-based assay for early prostate cancer antigen," Cancer Research, vol. 65, no. 10, pp. 4097-4100, 2005.

[25] S. Varambally, S. M. Dhanasekaran, M. Zhou et al., "The polycomb group protein EZH2 is involved in progression of prostate cancer," Nature, vol. 419, no. 6907, pp. 624-629, 2002.

[26] G. Hienert, J. C. Kirchheimer, H. Pfluger, and B. R. Binder, "Urokinase-type plasminogen activator as a marker for the formation of distant metastases in prostatic carcinomas," Journal of Urology, vol. 140, no. 6, pp. 1466-1469, 1988.

[27] H. Miyake, I. Hara, K. Yamanaka, S. Arakawa, and S. Kamidono, "Elevation of urokinase-type plasminogen activator and its receptor densities as new predictors of disease progression and prognosis in men with prostate cancer," International Journal of Oncology, vol. 14, no. 3, pp. 535-541, 1999.

[28] S. F. Shariat, C. G. Roehrborn, J. D. McConnell et al., "Association of the circulating levels of the urokinase system of plasminogen activation with the presence of prostate cancer and invasion, progression, and metastasis," Journal of Clinical Oncology, vol. 25, no. 4, pp. 349-355, 2007.

[29] J. Yu, J. Yu, R.-S. Mani et al., "An integrated network of androgen receptor, polycomb, and TMPRSS2-ERG gene fusions in prostate cancer progression," Cancer Cell, vol. 17, no. 5, pp. 443-454, 2010.
[30] N. Cerveira, F. R. Ribeiro, A. Peixoto et al., “TMPRSS2-ERG gene fusion causing ERG overexpression precedes chromosome copy number changes in prostate carcinomas and paired HGPIN lesions," Neoplasia, vol. 8, no. 10, pp. 826-832, 2006.

[31] K. Park, S. A. Tomlins, K. M. Mudaliar et al., "Antibody-based detection of ERG rearrangement-positive prostate cancer," Neoplasia, vol. 12, no. 7, pp. 590-598, 2010.

[32] G. J. Van Leenders, J. L. Boormans, C. J. Vissers et al., "Antibody EPR3864 is specific for ERG genomic fusions in prostate cancer: implications for pathological practice," Modern Pathology, vol. 24, no. 8, pp. 1128-1138, 2011.

[33] D. Gasi Tandefelt, J. Boormans, K. Hermans, and J. Trapman, "ETS fusion genes in prostate cancer," Endocrine-Related Cancer, 2014.

[34] D. Hessels, F. P. Smit, G. W. Verhaegh, J. A. Witjes, E. B. Cornel, and J. A. Schalken, "Detection of TMPRSS2-ERG fusion transcripts and prostate cancer antigen 3 in urinary sediments may improve diagnosis of prostate cancer," Clinical Cancer Research, vol. 13, no. 17, pp. 5103-5108, 2007.

[35] S. S. Salami, F. Schmidt, B. Laxman et al., "Combining urinary detection of TMPRSS2:ERG and CaP3 with serum PSA to predict diagnosis of prostate cancer," Urologic Oncology, vol. 31, no. 5, pp. 566-571, 2013.

[36] D. Hessels and J. A. Schalken, "Urinary biomarkers for prostate cancer: a review," Asian Journal of Andrology, vol. 15, no. 3, pp. 333-339, 2013.

[37] L. D. Truong, D. Kadmon, B. K. McCune, K. C. Flanders, P. T. Scardino, and T. C. Thompson, "Association of transforming growth factor- $\beta 1$ with prostate cancer: an immunohistochemical study," Human Pathology, vol. 24, no. 1, pp. 4-9, 1993.

[38] T. C. Thompson, L. D. Truong, T. L. Timme et al., "Transforming growth factor beta 1 as a biomarker for prostate cancer," Journal of cellular biochemistry Supplement, vol. 16, pp. 54-61, 1992.

[39] V. Ivanović, M. Demajo, K. Krtolica et al., "Elevated plasma TGF- $\beta 1$ levels correlate with decreased survival of metastatic breast cancer patients," Clinica Chimica Acta, vol. 371, no. 1-2, pp. 191-193, 2006.

[40] C. M. Grant and N. Kyprianou, "Epithelial mesenchymal transition (EMT) in prostate growth and tumor progression," Translational Andrology and Urology, vol. 2, no. 3, pp. 202-211, 2013.

[41] T. R. Samatov, A. G. Tonevitsky, and U. Schumacher, "Epithelialmesenchymal transition: focus on metastatic cascade, alternative splicing, non-coding RNAs and modulating compounds," Molecular Cancer, vol. 12, article 107, 2013.

[42] S. F. Shariat, M. Shalev, A. Menesses-Diaz et al., "Preoperative plasma levels of transforming growth factor betal (TGF- $\beta 1$ strongly predict progression in patients undergoing radical prostatectomy," Journal of Clinical Oncology, vol. 19, no. 11, pp. 2856-2864, 2001.

[43] Y. Matuo, N. Nishi, H. Takasuka et al., "Production and significance of TGF- $\beta$ in AT- 3 metastatic cell line established from the Dunning rat prostatic adenocarcinoma," Biochemical and Biophysical Research Communications, vol. 166, no. 2, pp. 840-847, 1990.

[44] D. Tan, X. Wu, M. Hou et al., "Interleukin-6 polymorphism is associated with more aggressive prostate cancer," Journal of Urology, vol. 174, no. 2, pp. 753-756, 2005.

[45] D. Giri, M. Ozen, and M. Ittmann, "Interleukin-6 is an autocrine growth factor in human prostate cancer," American Journal of Pathology, vol. 159, no. 6, pp. 2159-2165, 2001. 
[46] S. F. Shariat, M. W. Kattan, E. Traxel et al., "Association of preand postoperative plasma levels of transforming growth factor beta(1) and interleukin 6 and its soluble receptor with prostate cancer progression," Clinical Cancer Research, vol. 10, no. 6, pp. 1992-1999, 2004.

[47] A. Voulgari and A. Pintzas, "Epithelial-mesenchymal transition in cancer metastasis: Mechanisms, markers and strategies to overcome drug resistance in the clinic," Biochimica et Biophysica Acta, vol. 1796, no. 2, pp. 75-90, 2009.

[48] K. Gravdal, O. J. Halvorsen, S. A. Haukaas, and L. A. Akslen, "A switch from E-cadherin to $\mathrm{N}$-cadherin expression indicates epithelial to mesenchymal transition and is of strong and independent importance for the progress of prostate cancer," Clinical Cancer Research, vol. 13, no. 23, pp. 7003-7011, 2007.

[49] S. Sethi, J. Macoska, W. Chen, and F. H. Sarkar, "Molecular signature of epithelial-mesenchymal transition (EMT) in human prostate cancer bone metastasis," The American Journal of Translational Research, vol. 3, no. 1, pp. 90-99, 2011.

[50] B. M. Anose, L. Lagoo, and J. Schwendinger, "Characterization of androgen regulation of ZEB-1 and PSA in 22RV1 prostate cancer cells," Advances in Experimental Medicine and Biology, vol. 617, pp. 541-546, 2008.

[51] A. J. Armstrong, M. S. Marengo, S. Oltean et al., "Circulating tumor cells from patients with advanced prostate and breast cancer display both epithelial and mesenchymal markers," Molecular Cancer Research, vol. 9, no. 8, pp. 997-1007, 2011.

[52] V. V. Lukyanchuk, H. Friess, J. Kleeff et al., "Detection of circulating tumor cells by cytokeratin 20 and prostate stem cell antigen RT-PCR in blood of patients with gastrointestinal cancers," Anticancer Research, vol. 23, no. 3, pp. 2711-2716, 2003.

[53] O. Camara, M. Rengsberger, A. Egbe et al., "The relevance of circulating epithelial tumor cells (CETC) for therapy monitoring during neoadjuvant (primary systemic) chemotherapy in breast cancer," Annals of Oncology, vol. 18, no. 9, pp. 1484-1492, 2007.

[54] A. Armakolas, Z. Panteleakou, A. Nezos et al., "Detection of the circulating tumor cells in cancer patients," Future Oncology, vol. 6, no. 12, pp. 1849-1856, 2010.

[55] Z. Panteleakou, P. Lembessis, A. Sourla et al., "Detection of circulating tumor cells in prostate cancer patients: methodological pitfalls and clinical relevance," Molecular Medicine, vol. 15, no. 3-4, pp. 101-114, 2009.

[56] M. Thalgott, B. Rack, T. Maurer et al., "Detection of circulating tumor cells in different stages of prostate cancer," Journal of Cancer Research and Clinical Oncology, vol. 139, no. 5, pp. 755763, 2013.

[57] A. Rolle, R. Günzel, U. Pachmann, B. Willen, K. Höffken, and K. Pachmann, "Increase in number of circulating disseminated epithelial cells after surgery for non-small cell lung cancer monitored by MAINTRAC ${ }^{\circledR}$ is a predictor for relapse: a preliminary report," World Journal of Surgical Oncology, vol. 3, article 18, 2005.

[58] K. Pachmann, O. Camara, A. Kavallaris et al., "Monitoring the response of circulating epithelial tumor cells to adjuvant chemotherapy in breast cancer allows detection of patients at risk of early relapse," Journal of Clinical Oncology, vol. 26, no. 8, pp. 1208-1215, 2008.

[59] M. Pollak, "Insulin, insulin-like growth factors and neoplasia," Best Practice and Research: Clinical Endocrinology and Metabolism, vol. 22, no. 4, pp. 625-638, 2008.

[60] E. J. Gallagher and D. LeRoith, "The proliferating role of insulin and insulin-like growth factors in cancer," Trends in Endocrinology and Metabolism, vol. 21, no. 10, pp. 610-618, 2010.
[61] H. Werner and I. Bruchim, "IGF-1 and BRCA1 signalling pathways in familial cancer," The Lancet Oncology, vol. 13, no. 12, pp. e537-e544, 2012.

[62] J. M. Chan, M. J. Stampfer, J. Ma et al., "Insulin-like growth factor-I (IGF-I) and IGF binding protein-3 as predictors of advanced-stage prostate cancer," Journal of the National Cancer Institute, vol. 94, no. 14, pp. 1099-1106, 2002.

[63] G. O. Hellawell, G. D. H. Turner, D. R. Davies, R. Poulsom, S. F. Brewster, and V. M. Macaulay, "Expression of the type 1 insulinlike growth factor receptor is up-regulated in primary prostate cancer and commonly persists in metastatic disease," Cancer Research, vol. 62, no. 10, pp. 2942-2950, 2002.

[64] D. W. Voskuil, A. Bosma, A. Vrieling, M. A. Rookus, and L. J. Van 'T Veer, "Insulin-like growth factor (IGF)-system mRNA quantities in normal and tumor breast tissue of women with sporadic and familial breast cancer risk," Breast Cancer Research and Treatment, vol. 84, no. 3, pp. 225-233, 2004.

[65] C. J. Ryan, C. M. Haqq, J. Simko et al., "Expression of insulinlike growth factor-1 receptor in local and metastatic prostate cancer," Urologic Oncology: Seminars and Original Investigations, vol. 25, no. 2, pp. 134-140, 2007.

[66] G. Koliakos, D. Chatzivasiliou, T. Dimopoulos et al., "The significance of PSA/IGF-1 ratio in differentiating benign prostate hyperplasia from prostate cancer," Disease Markers, vol. 16, no. 3-4, pp. 143-146, 2000.

[67] J. M. Carboni, A. V. Lee, D. L. Hadsell et al., "Tumor development by transgenic expression of a constitutively active insulinlike growth factor I receptor," Cancer Research, vol. 65, no. 9, pp. 3781-3787, 2005.

[68] S. A. Rosenzweig and H. S. Atreya, "Defining the pathway to insulin-like growth factor system targeting in cancer," Biochemical Pharmacology, vol. 80, no. 8, pp. 1115-1124, 2010.

[69] E. R. King and K.-K. Wong, "Insulin-like growth factor: current concepts and new developments in cancer therapy," Recent Patents on Anti-Cancer Drug Discovery, vol. 7, no. 1, pp. 14-30, 2012.

[70] Y. Wang, J. Hailey, D. Williams et al., "Inhibition of insulinlike growth factor-I receptor (IGF-IR) signaling and tumor cell growth by a fully human neutralizing anti-IGF-IR antibody," Molecular Cancer Therapeutics, vol. 4, no. 8, pp. 1214-1221, 2005.

[71] F. J. Calzone, E. Cajulis, Y. A. Chung, M. M. Tsai, P. Mitchell, J. Lu et al., "Epitope-specific mechanisms of IGF1R inhibition by ganitumab," PLoS ONE, vol. 8, no. 2, Article ID e55135, 2013.

[72] A. G. Papatsoris, M. V. Karamouzis, and A. G. Papavassiliou, "Novel insights into the implication of the IGF-1 network in prostate cancer," Trends in Molecular Medicine, vol. 11, no. 2, pp. 52-55, 2005.

[73] M. N. Pollak, E. S. Schernhammer, and S. E. Hankinson, "Insulin-like growth factors and neoplasia," Nature Reviews Cancer, vol. 4, no. 7, pp. 505-518, 2004.

[74] P. De Meyts and J. Whittaker, "Structural biology of insulin and IGF1 receptors: implications for drug design," Nature Reviews Drug Discovery, vol. 1, no. 10, pp. 769-783, 2002.

[75] C. García-Echeverría, M. A. Pearson, A. Marti et al., "In vivo antitumor activity of NVP-AEW541-a novel, potent, and selective inhibitor of the IGF-IR kinase," Cancer Cell, vol. 5, no. 3, pp. 231-239, 2004.

[76] A. Bielen, L. Perryman, G. M. Box et al., "Enhanced efficacy of IGF1R inhibition in pediatric glioblastoma by combinatorial targeting of PDGFR $\alpha / \beta$," Molecular Cancer Therapeutics, vol.10, no. 8, pp. 1407-1418, 2011. 
[77] A. Arcaro, "Targeting the insulin-like growth factor-1 receptor in human cancer," Frontiers in Pharmacology, vol. 4, p. 30, 2013.

[78] J. Abraham, S. I. Prajapati, K. Nishijo et al., "Evasion mechanisms to Igflr inhibition in rhabdomyosarcoma," Molecular Cancer Therapeutics, vol. 10, no. 4, pp. 697-707, 2011.

[79] B. O. Nilsson, L. Carlsson, A. Larsson, and G. Ronquist, "Autoantibodies to prostasomes as new markers for prostate cancer," Upsala Journal of Medical Sciences, vol. 106, no. 1, pp. 43-50, 2001.

[80] S. V. Bradley, K. I. Oravecz-Wilson, G. Bougeard et al., "Serum antibodies to Huntingtin interacting protein-1: a new blood test for prostate cancer," Cancer Research, vol. 65, no. 10, pp. 41264133, 2005.

[81] O. J. Finn, "Immune response as a biomarker for cancer detection and a lot more," The New England Journal of Medicine, vol. 353, no. 12, pp. 1288-1290, 2005.

[82] J. E. Hansen, G. Chan, Y. Liu et al., "Targeting cancer with a lupus autoantibody," Science Translational Medicine, vol. 4, no. 157, Article ID 157ra42, 2012.

[83] X. Wang, J. Yu, A. Sreekumar et al., "Autoantibody signatures in prostate cancer," The New England Journal of Medicine, vol. 353, no. 12, pp. 1224-1235, 2005.

[84] B. S. Reis, A. A. Jungbluth, D. Frosina et al., "Prostate cancer progression correlates with increased humoral immune response to a human endogenous retrovirus GAG protein," Clinical Cancer Research, vol. 19, no. 22, pp. 6112-6125, 2013.

[85] H. Zhu, M. Bilgin, and M. Snyder, "Proteomics," Annual Review of Biochemistry, vol. 72, pp. 783-812, 2003.

[86] E. Pin, C. Fredolini, and E. F. Petricoin III, "The role of proteomics in prostate cancer research: biomarker discovery and validation. .," Clinical Biochemistry, vol. 46, no. 6, pp. 524538, 2013.

[87] Y. Hathout, "Approaches to the study of the cell secretome," Expert Review of Proteomics, vol. 4, no. 2, pp. 239-248, 2007.

[88] B. J. Trock, "Application of metabolomics to prostate cancer," Urologic Oncology, vol. 29, no. 5, pp. 572-581, 2011.

[89] M. J. Roberts, H. J. Schirra, M. F. Lavin, and R. A. Gardiner, "Metabolomics: a novel approach to early and noninvasive prostate cancer detection," Korean Journal of Urology, vol. 52, no. 2, pp. 79-89, 2011.

[90] L. C. Costello and R. B. Franklin, "Concepts of citrate production and secretion by prostate 1. Metabolic relationships," Prostate, vol. 18, no. 1, pp. 25-46, 1991.

[91] V. Kumar, D. K. Dwivedi, and N. R. Jagannathan, "Highresolution NMR spectroscopy of human body fluids and tissues in relation to prostate cancer," NMR in Biomedicine, vol. 27, no. 1, pp. 80-89, 2014.

[92] E. A. Struys, A. C. Heijboer, J. van Moorselaar, C. Jakobs, and M. A. Blankenstein, "Serum sarcosine is not a marker for prostate cancer," Annals of Clinical Biochemistry, vol. 47, no. 3, p. 282, 2010.

[93] A. Sreekumar, L. M. Poisson, T. M. Rajendiran et al., "Metabolomic profiles delineate potential role for sarcosine in prostate cancer progression," Nature, vol. 457, no. 7231, pp. 910914, 2009.

[94] M. Pavlou and E. P. Diamandis, "The search for new prostate cancer biomarkers continues," Clinical Chemistry, vol. 55, no. 7, pp. 1277-1279, 2009.

[95] J. Chen, J. Zhang, W. Zhang, and Z. Chen, "Sensitive determination of the potential biomarker sarcosine for prostate cancer by LC-MS with N, N'-dicyclohexylcarbodiimide derivatization," Journal of Separation Science, vol. 37, no. 1-2, pp. 14-19, 2014.
[96] M. G. Swanson, D. B. Vigneron, Z. L. Tabatabai et al., "Proton HR-MAS spectroscopy and quantitative pathologic analysis of MRI/3D-MRSI-targeted postsurgical prostate tissues," Magnetic Resonance in Medicine, vol. 50, no. 5, pp. 944-954, 2003.

[97] M. G. Swanson, K. R. Keshari, Z. L. Tabatabai et al., "Quantification of choline- and ethanolamine-containing metabolites in human prostate tissues using1H HR-MAS total correlation spectroscopy," Magnetic Resonance in Medicine, vol. 60, no. 1, pp. 33-40, 2008.

[98] T. Kobus, A. J. Wright, E. Weiland, A. Heerschap, and T. W. Scheenen, "Metabolite ratios in H MR spectroscopic imaging of the prostate," Magnetic Resonance in Medicine, 2014.

[99] T. Yoneyama, U. Tateishi, T. Terauchi, and T. Inoue, "Correlation of metabolic tumor volume and C-choline uptake with the pathology of prostate cancer: evaluation by use of simultaneously recorded MR and PET images," Japanese Journal of Radiology, vol. 32, no. 3, pp. 155-163, 2014.

[100] J. R. Dobosy, J. L. W. Roberts, V. X. Fu, and D. F. Jarrard, “The expanding role of epigenetics in the development, diagnosis and treatment of prostate cancer and benign prostatic hyperplasia," Journal of Urology, vol. 177, no. 3, pp. 822-831, 2007.

[101] C. Jerónimo, P. J. Bastian, A. Bjartell et al., "Epigenetics in prostate cancer: biologic and clinical relevance," European Urology, vol. 60, no. 4, pp. 753-766, 2011.

[102] T. A. Chan, S. Glockner, M. Y. Joo et al., "Convergence of mutation and epigenetic alterations identifies common genes in cancer that predict for poor prognosis," PLoS Medicine, vol. 5, no. 5, article el14, 2008.

[103] T. Wu, E. Giovannucci, J. Welge, P. Mallick, W.-Y. Tang, and S.-M. Ho, "Measurement of GSTP1 promoter methylation in body fluids may complement PSA screening: A meta-analysis," British Journal of Cancer, vol. 105, no. 1, pp. 65-73, 2011.

[104] M. Nakayama, C. J. Bennett, J. L. Hicks et al., "Hypermethylation of the human glutathione S-transferase- $\pi$ gene (GSTP1) $\mathrm{CpG}$ island is present in a subset of proliferative inflammatory atrophy lesions but not in normal or hyperplastic epithelium of the prostate: a detailed study using laser-capture microdissection," The American Journal of Pathology, vol. 163, no. 3, pp. 923-933, 2003.

[105] L. C. Li, S. T. Okino, and R. Dahiya, "DNA methylation in prostate cancer," Biochimica et Biophysica Acta, vol. 1704, no. 2, pp. 87-102, 2004.

[106] H. Enokida, H. Shiina, S. Urakami et al., "Multigene methylation analysis for detection and staging of prostate cancer," Clinical Cancer Research, vol. 11, no. 18, pp. 6582-6588, 2005.

[107] K. Kawamoto, S. T. Okino, R. F. Place et al., "Epigenetic modifications of RASSF1A gene through chromatin remodeling in prostate cancer," Clinical Cancer Research, vol. 13, no. 9, pp. 2541-2548, 2007.

[108] K. Chiam, C. Ricciardelli, and T. Bianco-Miotto, "Epigenetic biomarkers in prostate cancer: current and future uses," Cancer Letters, vol. 342, no. 2, pp. 248-256, 2014.

[109] H. Schwarzenbach, D. S. B. Hoon, and K. Pantel, "Cell-free nucleic acids as biomarkers in cancer patients," Nature Reviews Cancer, vol. 11, no. 6, pp. 426-437, 2011.

[110] D. B. Seligson, S. Horvath, T. Shi et al., "Global histone modification patterns predict risk of prostate cancer recurrence," Nature, vol. 435, no. 7046, pp. 1262-1266, 2005.

[111] H. Valadi, K. Ekström, A. Bossios, M. Sjöstrand, J. J. Lee, and J. O. Lötvall, "Exosome-mediated transfer of mRNAs and microRNAs is a novel mechanism of genetic exchange between cells," Nature Cell Biology, vol. 9, no. 6, pp. 654-659, 2007. 
[112] K. Wang, S. Zhang, J. Weber, D. Baxter, and D. J. Galas, "Export of microRNAs and microRNA-protective protein by mammalian cells," Nucleic Acids Research, vol. 38, no. 20, pp. 7248-7259, 2010.

[113] J. C. Brase, D. Wuttig, R. Kuner, and H. Sültmann, "Serum microRNAs as non-invasive biomarkers for cancer," Molecular Cancer, vol. 9, article 306, 2010.

[114] R. J. Bryant, T. Pawlowski, J. W. F. Catto et al., "Changes in circulating microRNA levels associated with prostate cancer," British Journal of Cancer, vol. 106, no. 4, pp. 768-774, 2012.

[115] P. P. Osin and S. R. Lakhani, "The pathology of familial breast cancer. Immunohistochemistry and molecular analysis," Breast Cancer Research, vol. 1, no. 1, pp. 36-40, 1999.

[116] L. M. Berstein, "Endocrinology of the wild and mutant BRCA1 gene and types of hormonal carcinogenesis," Future Oncology, vol. 4, no. 1, pp. 23-39, 2008.

[117] H. Eerola, P. Heikkilä, A. Tamminen, K. Aittomäki, C. Blomqvist, and H. Nevanlinna, "Relationship of patients' age to histopathological features of breast tumours in BRCA1 and BRCA2 and mutation-negative breast cancer families," Breast Cancer Research, vol. 7, no. 4, pp. R465-R469, 2005.

[118] C. M. Barnett, M. C. Heinrich, J. Lim, D. Nelson, C. Beadling, A. Warrick et al., "Genetic Profiling to Determine Risk of Relapse Free Survival in High-risk Localized Prostate Cancer," Clinical Cancer Research, vol. 20, no. 5, pp. 1306-1312, 2013.

[119] J. R. Schoenborn, P. Nelson, and M. Fang, "Genomic profiling defines subtypes of prostate cancer with the potential for therapeutic stratification," Clinical Cancer Research, vol. 19, no. 15, pp. 4058-4066, 2013.

[120] B. D. Hudson, K. S. Kulp, and G. G. Loots, "Prostate cancer invasion and metastasis: insights from mining genomic data," Briefings in Functional Genomics, vol. 12, no. 5, pp. 397-410, 2013.

[121] A. Amaro, A. I. Esposito, A. Gallina, M. Nees, G. Angelini, A. Albini et al., "Validation of proposed prostate cancer biomarkers with gene expression data: a long road to travel," Cancer and Metastasis Reviews, 2014. 


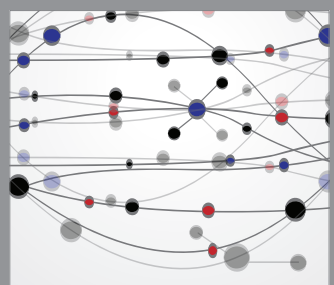

The Scientific World Journal
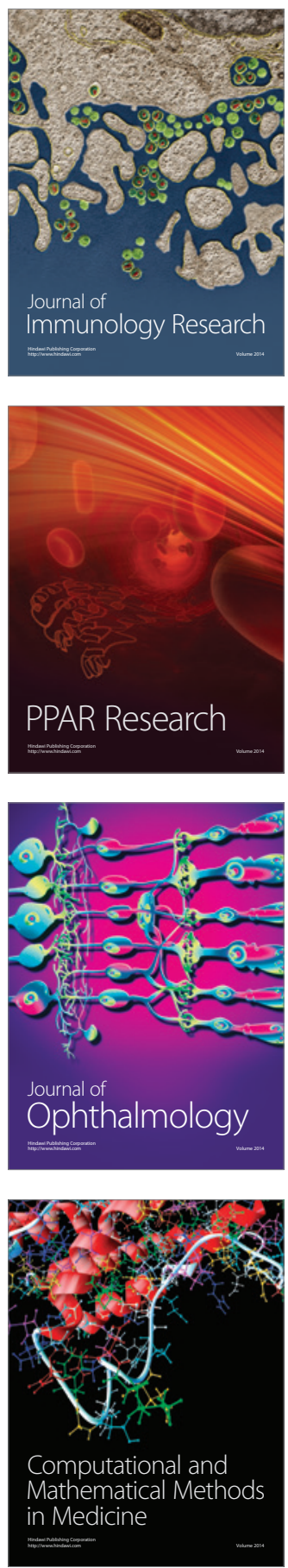

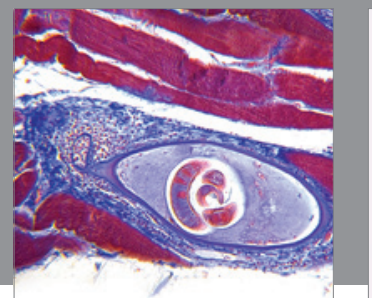

Gastroenterology

Research and Practice
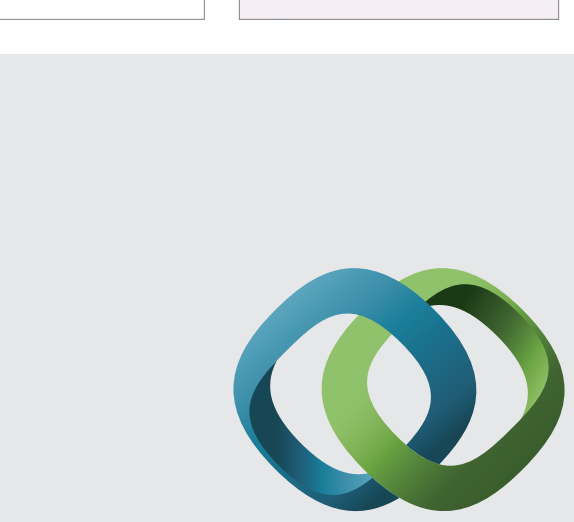

\section{Hindawi}

Submit your manuscripts at

http://www.hindawi.com
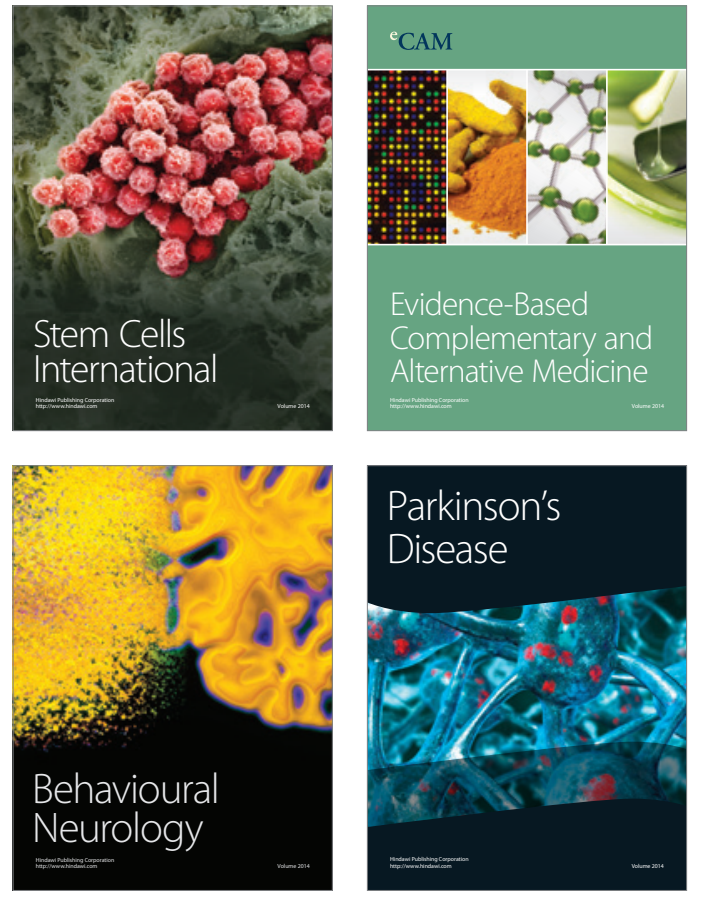
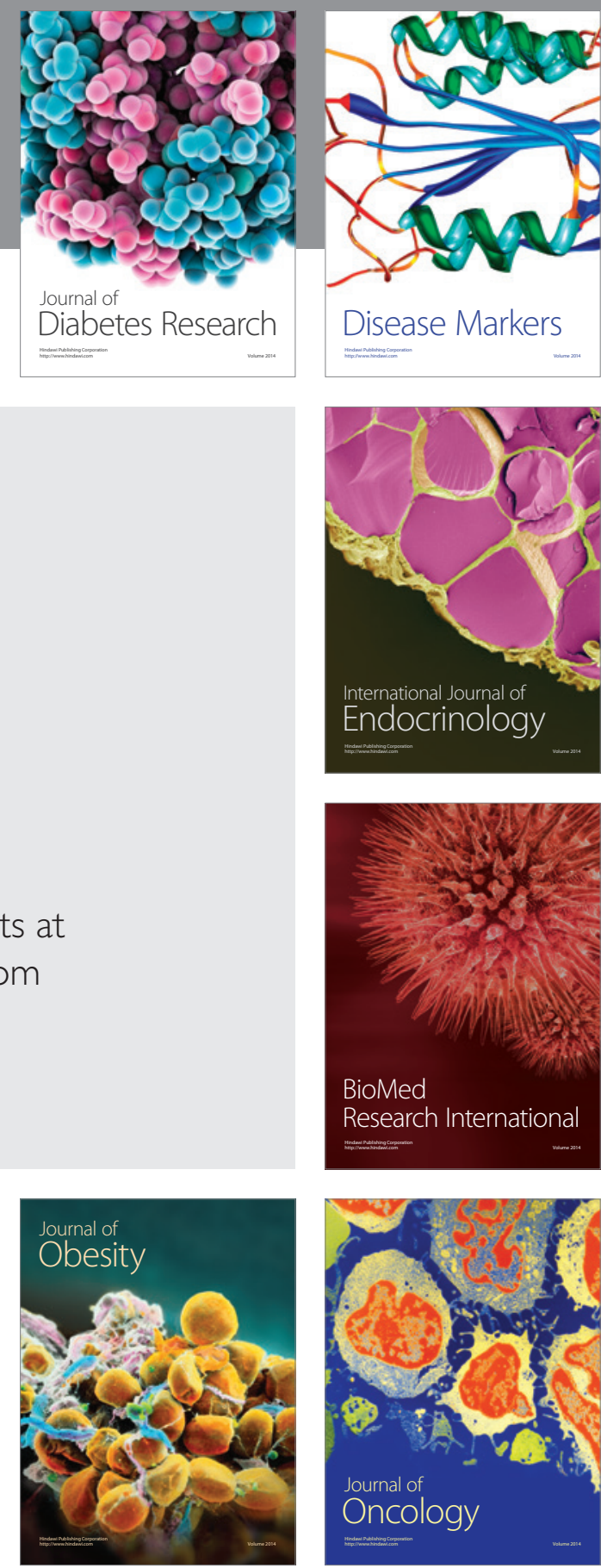

Disease Markers
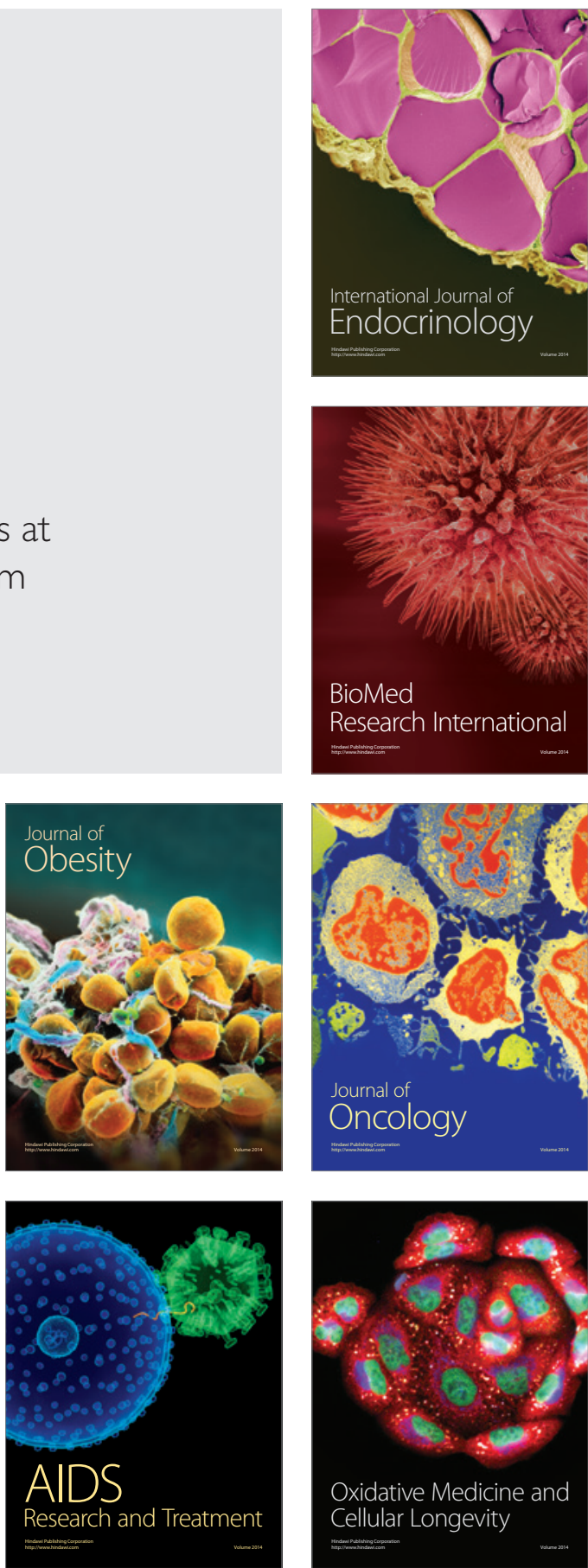